\title{
A COMPANHIA HIDRELÉTRICA TELES PIRES E O DISCURSO DO MITO DO PROGRESSO
}

\section{ARTIGO ORIGINAL}

CHAVES, Sidney da Silva ${ }^{1}$

COELHO, Micaela Pafume ${ }^{2}$

CHAVES, Sidney da Silva. COELHO, Micaela Pafume. A companhia hidrelétrica Teles Pires e o discurso do mito do progresso. Revista Científica Multidisciplinar Núcleo do Conhecimento. Ano 05, Ed. 03, Vol. 06, pp. 103-126. Março de 2020. ISSN: 2448-0959, Link de acesso: https://www.nucleodoconhecimento.com.br/letras/mitodo-progresso

\section{RESUMO}

Neste artigo, propomo-nos a analisar o discurso do mito do progresso utilizado pela Companhia Hidrelétrica Teles Pires (CHTP) como medida paliativa à construção da Usina Hidrelétrica Teles Pires (UHE Teles Pires), localizada nos municípios de Paranaíta - norte de Mato Grosso - e de Jacareacanga - sul do Pará - mas que traz impactos ao município de Alta Floresta - norte de Mato Grosso - pelo fato de ser área de influência indireta. Nesse sentido, a CHTP, estrategicamente, desde o início da construção da Barragem, propaga na mídia regional o discurso do mito do progresso

\footnotetext{
${ }_{1}^{1}$ Mestrando em Educação, Especialista em Língua Portuguesa-Unemat- Universidade Estadual de Mato Grosso; Especialista em Didática do Ensino Superior- FIUFaculdade Integradas de Educação, Ciências e Letras de Urubupungá; Especialista em História de Mato Grosso- IFMT- Instituto Federal de Educação, Ciência e Tecnologia de Mato Grosso. Graduado em Letras- Fecilcam- Faculdade Estadual de Campo Mourão-PR; Graduado em História- Unemat- Universidade estadual de Mato Grosso.
}

2 Doutora em Estudos Linguísticos pela Universidade Federal de Uberlândia. 
para convencer a população de que o empreendimento vem trazendo progresso para a região e levando bem-estar e qualidade de vida à população. Este estudo, então, é fundamentado pelo viés da análise do discurso veiculado na mídia pela CHTP. Para esta análise, selecionamos três notícias publicadas no jornal "O Diário", da cidade de Alta Floresta. Nossa interpretação foi somente ao olhar da produção do discurso, mas também à historicidade direcionada não dos fatos e dos agentes que produzem e que são influenciados por este discurso. Assim, nessas notícias, verificamos que, após o término da UHE Teles Pires, a CHTP continua propagando a chegada do progresso a fim de desconstruir sua imagem negativa perante a população. $O$ discurso empregado agora é o de preservadora e protetora do meio ambiente, ou seja, o desenvolvimento da região depende da preservação da natureza, sendo assim, um discurso paradoxal. Com a análise dos documentos selecionados, chegamos à conclusão de que o discurso da CHTP está sempre se renovando, a fim de preservar a imagem da empresa.

Palavras-chave: Discurso, mito do progresso, história de Mato Grosso.

\section{INTRODUÇÃO}

Alta Floresta está localizada no extremo norte do estado de Mato Grosso, a cerca de $830 \mathrm{~km}$ da capital do Estado, Cuiabá. O empreendimento denominado Usina Hidrelétrica Teles Pires (UHE Teles Pires) está situado nos municípios de ParanaítaMT e de Jacareacanga-PA. Sua construção tem influência no município de Alta Floresta, por este ser considerado área de influência indireta, haja vista que a barragem não foi construída no município, mas, por ser cidade polo, sofre impactos ocasionados pelo inchaço populacional, acarretando aumento da violência. Além disso, é nesse município que se concentram os equipamentos e serviços públicos oferecidos aos funcionários da usina.

Nesse sentido, a cidade sofre os maiores impactos socioeconômicos, pois milhares de trabalhadores, atraídos pelo empreendimento, de uma forma ou de outra, foram "acolhidos". Inclusive, é nesse município em que se encontra a sede do escritório central da Companhia Hidrelétrica Teles Pires (CHTP), bem como a moradia a seus 
diretores; e é nele que são oferecidos os serviços de maior qualidade, como hospitais, escolas, rede de agência bancária, aeroporto, dentre outros.

Ainda hoje, mesmo com a UHE -Teles Pires já concluída, Alta Floresta sente impactos relevantes provenientes de sua instalação, devido à falta de planejamento e suporte. Afinal, as obras de compensação e de mitigação não foram aplicadas de forma a garantir o bem-estar da população atingida - não só de Alta Floresta, área de influência indireta, mas também dos municípios que constituem área de influência direta, principalmente Paranaíta.

Desse modo, destacamos em Chaves (2015) que, no contexto da época, a CHTP utilizava um discurso veiculado na mídia para "vender" o mito do progresso e mostrar que a companhia estava cumprindo com a legislação e realizando as obras de mitigação e de compensação à vida da população atingida. Também notamos ser a mídia apenas reprodutora do discurso da usina, contribuindo assim para a propagação desse discurso e para a não criticidade sobre o empreendimento, impedindo que a população atingida conhecesse os verdadeiros interesses que estavam por trás da construção da UHE Teles Pires.

Tendo isso em vista, neste artigo, propomo-nos a avançar a respeito dessa questão, buscando evidenciar de que modo o mito do discurso do progresso ainda sustenta as reportagens relacionadas à UHE Teles Pires. Especificamente, buscamos analisar o discurso utilizado pela CHTP, em artigos veiculados no jornal "O Diário" de Alta Floresta, em sua versão impressa nos meses de agosto e setembro de 2016. Essa escolha se justifica, pois, nesses meses, observou-se que, após um tempo de silenciamento por parte da CHTP, esta voltou à mídia destacando sua atividade de preservação do meio ambiente. A escolha de analisar as notícias veiculadas no jornal "O Diário" se dá pelo fato de este ser o veículo de comunicação escrito de maior abrangência e ainda ser o principal jornal dos municípios de Alta Floresta e Paranaíta.

Para a realização deste trabalho, selecionamos as fontes documentais veiculadas no jornal "O Diário", principal jornal do município de Alta Floreta-MT, que nos meses de agosto e setembro, publicou notícias sobre a CHTP. Nesses documentos, buscamos 
interpretar a renovação do discurso do mito do progresso utilizado pela empresa, pois o empreendimento foi finalizado, mas o progresso não veio, como prometido no início e no decorrer da construção da barragem.

Por intermédio das matérias publicadas pela assessoria da CHTP no jornal citado, nossa interpretação é direcionada não somente ao olhar da produção do discurso, mas também à historicidade dos fatos e dos agentes que produzem e que são influenciados por este discurso. Afinal, o progresso existe ou é um mito que necessita sempre ser renovado e seus agentes sempre (re)conquistados?

Nessa linha de pensamento é interpretamos os documentos publicados no jornal "O Diário". Temos consciência de que o campo de análise em qualquer documento é vasto e nunca se esgota, principalmente quando se trata de discurso, de mito e de progresso numa região ainda em formação e em que a população está sedenta por progresso para melhorar sua vida quanto à saúde, à educação, à segurança, à qualidade de vida e à economia. O sonho de que "dias melhores virão" nunca se acaba numa região tão distante de centros econômicos e políticos do país, como São Paulo e Rio de Janeiro, locais onde, para os moradores da região amazônica, o progresso já chegou.

Desse modo, para efetuar o trabalho proposto, utilizamos como corpus de análise, especificamente, três notícias[3] publicadas no jornal "O Diário". Elas são datadas dos dias 12/08/2016, 17/08/2016 e 27/09/2016. Além disso, nossa pesquisa teve como método principal a análise bibliográfica, tanto do corpus selecionado, como também de textos e livros de autores que tratam acerca do mito do discurso do progresso.

\section{O DISCURSO DO MITO DO PROGRESSO E SEUS SENTIDOS}

Para analisar de que modo a CHTP se utiliza do discurso do mito do progresso para minimizar a propagação de uma imagem negativa na região em que está instalada, consideramos, primeiramente, necessário refletir sobre esse conceito chave. Entender em que consiste o discurso do mito do progresso é fundamental para que consigamos evidenciá-lo no contexto em que a CHTP se insere. 
Foucault (1970, p. 10) aponta o discurso como "socialmente construído e socialmente legitimado. O discurso é aquilo pelo que se luta; é o poder pelo qual nós queremos nos apoderar!". Assim é força de poder. Suas multiplas faces fazem parte de uma estratégia de dominação. É nele que as forças ideológicas se sustentam e ganham força de dominação. Fiorin (1993, p.35) colabora ao dizer "o homem aprende como ver o mundo pelos discursos que assimila e, na maior parte das vezes, reproduz esses discursos em sua fala".

Nesse limiar é que se sustenta o discurso da CHTP ao utilizar desses mecanismos discursivos para convencer a população da região atingida pela UHE Teles Pires a propagar o discurso do mito do progresso, agora, na ótica da preservação do meio ambiente. Este, antes, era degradado pela própria empresa ao construir a barragem, por não seguir todos os termos da Lei.

No que tange ao conceito de progresso, ressaltamos uma das definições apresentadas em Aurélio (2004): "desenvolvimento ou alteração em sentido favorável; avanço, melhoria." Esta abordagem coaduna de uma forma mais apropriada para a discussão aqui proposta. Nesse sentido, o progresso é o avanço, e traz, quase sempre, a ideia do novo, de melhores condições de vida para uma região, sendo uma ideia de evolução social.

Segundo Martins (1999, p. 64) as origens da ideia de "progresso" podem ser localizadas na antiga Grécia, nas teorias do filósofo Epicuro (341 - 270 AC). O autor define "O progresso social passa a ser compreendido econômico, ensejando posteriormente a noção de desenvolvimento (impulsão de algumas economias) e como corolário à noção de subdesenvolvimento. (MARTINS, 1999, p. 66).

Por isso, a construção de uma barragem para uns traz progresso; para outros acarreta "regresso". Assim, a sociedade acaba se frustrando, pois "a noção de desenvolvimento passa a

constituir-se em meia-verdade, ideia-metade, pseudo-idéia", tal como conclui Martins (1999, p.66). Desse modo, ressaltamos 
O discurso do progresso sempre permeou a política de expansão do capitalismo e no Brasil não foi diferente. Em se tratando do Norte de Mato Grosso este discurso, a princípio, veio enraizado ideologicamente na voz do colonizador, agente de uma política de integração nacional que teve início com a "Marcha para o Oeste" no governo varguista, na década de 1930. (CHAVES, 2015, p.10).

O discurso do mito do progresso é o que se busca, é o que se sonha, é o que se deseja. É o renovar dos sonhos de um povo, é o "avante!". Significa levantar no imaginário popular a sensação de que sonhos e expectativas de "dias melhores virão". Nesse sentido, vale destacar que o principal significado da palavra grega mythos - da qual a palavra "mito" deriva - é fábula. Dentre outros sentidos, há também o de "ideia falsa, sem correspondência com a realidade, [...] representação (passada ou futura) de um estágio ideal da humanidade[...], coisa inacreditável, fantasiosa, irreal; utopia." (FERREIRA, 1999, p. 1347 apud PLEIN; FILIPPI, 2012, p.14).

Contribuindo para esta discussão, Rocha (1994, p. 12) cita que "[...] mito é, pois, capaz de ser efetivo e, portanto, verdadeiro como estímulo forte para conduzir tanto o pensamento quanto o comportamento do ser humano ao lidar com realidades existenciais importantes."

Por isso, o mito do progresso é o que se impõe em regiões onde se quer conquistar a população, no sentido de que esta não só aceite o novo empreendimento como também contribua para a implantação deste e o defenda junto à comunidade.

Por outro lado, a ideia de progresso se coaduna com as de satisfação, de felicidade, de bem-estar de determinada sociedade. Esse bem-estar está associado, por exemplo, a serviços públicos de qualidade, ao desenvolvimento econômico (empregos, casa própria, salário digno para sustentar a família, lazer etc.). Relacionase também à educação de qualidade e ao bem- estar de alunos, à saúde para toda a população, e à possibilidade de crescer na vida. Assim, o mito do progresso seduz os indivíduos de uma sociedade, principalmente quando o local onde se vive está carente de desenvolvimento econômico. Como afirma Pádua (2016, p.1) "é nítido o anseio de 
muitos quererem obter empregos ou enormes riquezas, mesmo que historicamente os bem-sucedidos tenham sido poucos e, em muitos casos, como consequência da exploração de outros seres humanos e da natureza."

Mendonça e Porto (2008), no artigo "Do Progresso à busca pelo Meio Ambiente Equilibrado: a (in)compatibilidade da Tutela na Amazônia", ressaltam que

A noção de progresso é inerente ao imaginário construído pela chamada civilização moderna. A polissemia da palavra progresso guarda um traço em comum: a linearidade de um movimento no sentido de alcançar, qualitativa e quantitativamente, um patamar superior ao atual (MENDONÇA; PORTO, 2008, p. 1).

O progresso, como se nota na citação acima, é inseparável do homem. Sempre esteve presente no imaginário da sociedade, mas não com uma significação monossêmica. Seu sentido é modificado conforme a sociedade vai evoluindo e seu ritmo é ditado pelos novos desejos e pelas novas necessidades que a sociedade demanda. Nesse sentido, sua busca é vista como uma evolução. Por outro lado, é fundamental compreender que, diante da concepção de modernidade alardeada pelo sentido que o termo progresso traz, há um confronto, pois "nega outros modos de vida, nega outros ritmos, ao considerá-los e rotulá-los como atrasados, não evoluídos, não civilizados ou subdesenvolvidos" (MENDONÇA; PORTO, 2008, p. 3).

Expandindo esta definição, podemos dialogar com Bresser-Pereira (2014). O autor contribui ao mencionar que o progresso não é linear, pois é conflito e também fruto de dominação. Segundo ele

O progresso é sempre o produto de uma construção social, mas o caminho para ele não é nem pacífico, nem linear; é um processo de tentativa e erro, onde os agentes carecem da capacidade de prever com razoável precisão as consequências de suas ações; é um processo conflituoso nos níveis individual, grupal e de classe social, no qual os conflitos são resolvidos às vezes pelo encontro de uma terceira 
alternativa que atende aos dois lados, mas geralmente é pelo uso da força ou por meio de compromissos políticos. Esse conflito pode assumir uma forma leve e positiva quando expresso na competição, mas é quase sempre o produto de uma dominação, e se expressa em exploração e revolta (BRESSER-PEREIRA, 2014, p. 4).

O tempo passa, mas o discurso das empresas e das instituições tem de convencer, mesmo que os resultados esperados para a população não venham. Nesse sentido é que se trabalha o discurso do mito. A história traz seus mitos, suas verdades, ambos construídos sempre no dizer do dominador. Contudo, para que isso funcione, é importante "ganhar" a população local, conquistar a imprensa local e regional, convencer os políticos da região em que o evento será realizado. Além disso, investir em matérias positivas, em propagandas e patrocinar eventos populares é fundamental para que a imagem da empresa seja positiva perante a população.

Dessa forma, o capitalismo, em nome do progresso, ou seja, por intermédio do discurso do mito do progresso, semeia sonhos, mas gera conflitos de vários níveis: i) agrários (desapropriação de terras); ii) de ordem econômica (mudança da economia local: especulação imobiliária, aumento de aluguel, valorização de terrenos, aumento de preço de mão de obras das construções civis, aumento no movimento dos comércios e das agências bancárias etc.); iii) na educação (aumento de alunos nas escolas, por exemplo, gerando falta de salas de aulas, de professores, de material escolar, de meio de transporte e outros); iv) na saúde (lotação dos hospitais públicos e privados e dos postos de saúde, falta de ambulâncias, dentre outros); v) no transporte (aumento das frotas de veículos, por exemplo); vi) na segurança (aumento da criminalidade e de ocorrência policial, prostituição infantil, falta de contingente para atender a demanda policial, falta de viaturas, dentre outros).

Então, o "discurso do progresso e do desenvolvimento" ganha forma e força na mente dos atingidos, por meio da recorrência da logomarca e do nome da empresa em propagandas, patrocínios e incentivos. Provas disso são as campanhas contra a dengue, a malária e a hanseníase, por exemplo; bem como as campanhas contra 
drogas, álcool e a realização de reuniões, audiências públicas e seminários para "prestar contas" e/ou "debater" assuntos relacionados à população.

Apesar disso, parte da população é mera espectadora do evento e não seu protagonista, uma vez que tudo faz parte da estratégia para conquistar a população local. Essas ações são direcionadas sempre ao objetivo de criar uma nova imagem da empresa na região. Dessa forma, comprar a imprensa local com matérias pagas e propagandas da empresa e lançar informativos para divulgar "seus investimentos" faz parte do plano dessas empresas.

Assim, o discurso do mito do progresso vai se consolidando no imaginário da população como verdade e a usina desconstrói, aos poucos, a ideia negativa, mostrando que está comprometida com o bem-estar da população. O discurso da barragem, muitas vezes, é legitimado pela mídia local e regional e também pelos políticos. Estes deveriam se posicionar de forma crítica em relação ao empreendimento. Contudo, com o decorrer do tempo, a barragem é finalizada e os sonhos de uma vida melhor morrem junto com ela. Mais do que isso, a sociedade, muitas vezes, nem percebe que "o sonho acabou", mas sente seus efeitos colaterais todos os dias por exemplo o aumento da violência, a obra de mitigação que não foi realizada, a infraestrutura da cidade que não mudou, dentre outros.

Dialogando com Dupas (2007, p.73), consideramos importante ressaltar que "[...] esse progresso, discurso dominante das elites globais, traz também consigo exclusão, concentração de renda, subdesenvolvimento e graves danos ambientais, agredindo e restringindo direitos humanos essenciais." Complementado, deve ser destacado que os capitais nacional e estrangeiro têm se unido para conquistar e dominar territórios que Ihes rendem lucros exorbitantes, principalmente os mais fragilizados socialmente, em que a se apregoa o discurso do "espaço vazio", onde o outro se torna invisível.

Sendo assim, são as regiões mais longínquas do centro financeiro e político, que têm o objetivo de expandir suas riquezas, construir e fortalecer seus poderes financeiros e políticos. Por isso, reiteramos 
Mato Grosso tem sido e ainda continua sendo um estado onde a renovação da esperança de uma vida melhor está sempre em evidência. Esse discurso não é por acaso, até porque é um estado pouco povoado e rico em recursos naturais que podem ser explorados: recheado de terras por abrir e produtivas, há ainda uma vastidão de água, ouro, madeira, além de sua beleza natural. Tudo isso encanta e atrai investidores de todos os segmentos empresariais seduzidos pelo potencial de crescimento do estado. Dessa forma, o avanço da fronteira capitalista e ocupação dessa elite naquele espaço foi e continua sendo objeto de desejo e de domínio de território. (CHAVES, 2015, p.13).

Diante disso, o mito do progresso vai se renovando historicamente, com uma rapidez e estupidez humana gritante, uma vez que "hoje, tudo se converte em instantaneidade e proximidade." (DUPAS, 2007, p.79). Isso pode ser mais bem compreendido se pensarmos que, de acordo com o autor, a queda da Bastilha e o trágico terremoto de Lisboa demoraram meses até serem noticiados em cidades mais longínquas.

Dialogando com Dupas (2007, p.73), consideramos importante ressaltar seu dizer "[...] esse progresso, discurso dominante das elites globais, traz também consigo exclusão, concentração de renda, subdesenvolvimento e graves danos ambientais, agredindo e restringindo direitos humanos essenciais." Complementado, deve ser destacado que os capitais nacional e estrangeiro têm se unido para conquistar e dominar territórios que thes rendem lucros exorbitantes, principalmente os mais fragilizados socialmente, em que a se apregoa o discurso do "espaço vazio", onde o outro se torna invisível.

Isso mostra que é preciso refletir sobre as modificações impostas ao meio. A tendência capitalista do mundo contemporâneo e globalizado flui com uma rapidez estratégica que não dá tempo para as pessoas pensarem sobre o que é melhor para si e para sua comunidade, cidade ou região. O caso das usinas hidrelétricas mostra bem isso, pois seus discursos são carregados de esperanças de um futuro melhor para a região: empregos, progresso, o sonho da casa própria, do carro novo, o movimento no comércio, traz uma agitação no cotidiano das pessoas não deixando tempo para se pensar no futuro, afinal, "o futuro é o agora". Dessa forma, o mito do progresso é 
construído sem dar tempo para se pensar nas consequências que uma barragem pode causar a uma região.

O discurso do mito do progresso, então, na contemporaneidade, é produzido estrategicamente, de modo que não deixa o indivíduo refletir acerca de sua própria realidade. Ele deve ser iludido, engolido por este discurso ideologicamente construído. Como diz Dupas

(2007, p.79), "o indivíduo exposto e condicionado a essa monótona banalização exclui-se, descuida-se; sente-se pertencente ao todo, menos a ele mesmo."

É inegável que todos aceitam o desenvolvimento, no entanto, este não pode ser fruto de um capitalismo selvagem, desonesto, mentiroso e devorador, no qual só um lado ganha: o dos empreendedores e do grupo político que está no poder. O outro lado, o da perda, em que estão a sociedade que vive no centro urbano (afetados indiretamente) e a população ribeirinha e a natureza, que são diretamente afetadas pelas barragens, também deve poder usufruir do seu espaço social. Entretanto, o discurso do mito do progresso é tão avassalador que coloca o indivíduo numa posição em que este se envergonha de contestá-lo, afinal, quem é contra o progresso, é contra a população local, é contra o desenvolvimento de sua cidade e de sua região.

Além disso, é necessário apontar que há uma falsa democratização na discussão das ideias acerca da implantação de um grande investimento numa determinada localidade. Isso porque tudo já vem pronto, feito pelos agentes do capital, visto que são eles que escolhem e determinam a direção e os objetivos que circundam um povo. O futuro de uma localidade é decidido nos bastidores, por "meia dúzia" de pessoas visando seus próprios interesses econômicos.

Deve-se ressaltar que o capitalismo é um sistema que se sustenta pelo motivo de ser, até então, o único que bem ou mal, como cita Dupas (2007, p. 81), mantém a máquina econômica em movimento, pois nenhum outro sistema, diz o autor, aparece no horizonte como alternativa, mesmo que em forma de utopia. Então, esse sistema sustenta a máquina da "maior riqueza para os já ricos, enquanto que para os pobres 
sobra apenas algumas migalhas, ou melhor dizendo, algumas vantagens para os pobres, grandes vantagens para os ricos" (DUPAS, 2007, p.81).

Nesse mesmo sentido, Picoli (2004, p. 28) acentua que "os grandes empreendimentos encontraram todo um aparato que interessa à elite dominante do país, sempre amparada por leis protecionistas que contribuem para a expansão capitalista [...]". E, dessa forma, o mito do progresso é (re)construído sempre. Está sempre se renovando como (ou com) o capitalismo.

O discurso do mito do progresso veiculado em algumas reportagens do jornal "O diário" pela UHTP - Usina Hidrelétrica Teles Pires, objeto de estudo deste trabalho, não foge à discussão, uma vez que os investidores procuram negar a existência da população atingida, bem como suas culturas e organização social, tornando essa população invisível, já que elas não são ouvidas. Isso ocorre pelo fato de o projeto do empreendimento vir pronto: ou se negocia a propriedade para o empreendedor de forma amigável e pelo preço que este ofertar ou será desabrigado forçadamente com o aval do Estado.

\section{METODOLOGIA}

Para a realização deste trabalho, selecionamos as fontes documentais veiculadas no jornal "O Diário", principal jornal do município de Alta Floreta-MT, que, nos meses de agosto e setembro, publicou notícias sobre a CHTP. Nesses documentos, buscamos interpretar a renovação do discurso do mito do progresso utilizado pela empresa, já que o empreendimento foi finalizado, mas o progresso não veio, como prometido no início e no decorrer da construção da barragem.

Por intermédio das matérias publicadas pela assessoria da CHTP no jornal citado, nossa interpretação é direcionada não somente ao olhar da produção do discurso, mas também à historicidade dos fatos e dos agentes que produzem e que são influenciados por este discurso. Afinal, o progresso existe ou é um mito que necessita sempre ser renovado e seus agentes sempre (re)conquistados? 
Nessa linha de pensamento é que interpretaremos os documentos publicados no jornal "O Diário". Temos consciência de que o campo de análise em qualquer documento é vasto e nunca se esgota, principalmente quando se trata de discurso, de mito e de progresso numa região ainda em formação e em que a população está sedenta por progresso para melhorar sua vida quanto à saúde, à educação, à segurança, à qualidade de vida e à economia. O sonho de que "dias melhores virão" nunca se acaba numa região tão distante de centros econômicos e políticos do país, como São Paulo, local onde, para os que moram na região amazônica, o progresso já chegou.

Desse modo, para que possamos efetuar o trabalho proposto, utilizamos como corpus de análise, especificamente, três notícias ${ }^{4}$ publicadas no jornal “ O Diário”. Elas são datadas dos dias 12/08/2016, 17/08/2016 e 27/09/2016. Além disso, nossa pesquisa teve como método a análise bibliográfica, tanto do corpus selecionado, como também de textos e livros de autores que tratam acerca do mito do discurso do progresso.

\section{O JORNAL “O DIÁRIO” E O DISCURSO DA CHTP}

Como vimos, um discurso que se configura como "mito do progresso" consiste em uma construção linguístico-ideológica que visa passar a falsa impressão da instauração do progresso em determinado local. De maneira específica, é importante ressaltar que o discurso utilizado pela CHTP é construído estrategicamente para "ganhar" a população do Norte de Mato Grosso, onde a barragem está sendo construída, a fim de desconstruir a imagem negativa dessa empresa perante a população. Isso ocorre, pois uma empresa de barragem é sempre vista como destruidora do meio ambiente. Essa ótica é agravada pelo fato de ela não realizar as obras de mitigação e de compensação previstas em lei, para que pudesse, ao menos, minimizar os impactos que causa tanto à natureza (extinção de animais silvestres, plantas, peixes, assoreamento dos rios etc.) quanto à população da região. Isso não é diferente com a Companhia Hidrelétrica Teles Pires.

O ambiente destruído por uma empresa de barragem, no caso, a CHTP, deve ser compensado por obras de mitigação e de compensação. As primeiras são aquelas 
realizadas para minimizar os impactos ambientais causados pelo empreendimento; as segundas são realizadas para compensar os impactos decorrentes daquelas. Por exemplo, a mortandade de peixes é inevitável na construção de uma usina hidrelétrica, mas pode ser reduzida, caso haja um planejamento que abranja uma obra de mitigação. No que tange às obras de compensação, estas são realizadas quando os impactos causados não têm como serem atenuados, como o represamento do rio para a construção da represa. Neste caso, é necessário compensar os danos causados com outro investimento. Esses dois tipos de obras são de responsabilidade da CHTP.

Como já citado, a construção da UHE Teles Pires tem influência no município de Alta Floresta-MT, por este ser considerado área de influência indireta. Isso ocorre, pois a cidade é o polo regional que concentra os equipamentos de suporte da UHE e os serviços públicos mais estruturados, como bancos, hospitais públicos e particulares, escolares públicas e particulares, universidades públicas, particulares e à distância, maior rede de comércio, hotéis, lojas, entre outros. Nesse sentido, como já mencionado, o município sofreu e ainda sofre diretamente os impactos socioeconômicos deixados pela UHE Teles Pires, devido ao não cumprimento das obras de compensação e de mitigação asseguradas pela lei.

Considerando isso, ao procurarmos por evidências de realização de alguma ação compensatória por parte da empresa, notamos que, nos meses de agosto e de setembro de 2016, o principal jornal de Alta Floresta, o "O Diário", tem publicado notícias da UHE Teles Pires. Nelas, é possível observar que, novamente, a CHTP tem utilizado estratégias discursivas na imprensa local e regional para reacender o discurso do mito do progresso. Desta vez, focando mais na preservação do meio ambiente.

É notório que um empreendimento dessa magnitude "mexe" com a estrutura de uma cidade. A (in)certeza do progresso fica latente na mente de todos. Desse modo, "a construção de hidrelétricas transforma diversas frações do território e causa importantes e variados problemas políticos e sociais para as populações que ali vivem", escreve Nascimento et al. (2013, p. 2). O impacto político se dá, no tocante às 
negociações, envolvendo os mais diversos seguimentos sociais, principalmente o prefeito, os vereadores, os clubes de serviços, como Lions, Rotary e Maçonarias, presidentes de bairros, imprensa local e regional e etc. Esses são os agentes que ajudam a "vender" a ideia do mito do progresso, portanto, conquistá- los é fundamental.

O que se pode perceber é que, com o passar do tempo, mesmo com o empreendimento já concluído e sem o progresso que foi alardeado no início e no decorrer da construção da barragem, é preciso continuar a ideia de que tudo deu certo. Para isso, patrocinar eventos, como shows, esportes e realizar campanhas de cunho social (contra a dengue e outras doenças), bem como a conscientização sobre o meio ambiente e sobre as queimadas, são estratégias utilizadas pelas usinas hidrelétricas para continuarem vendendo a ideia de que estão contribuindo para o bem-estar da população atingida. Manter-se na mídia de forma positiva é importante.

Tendo isso em vista, ao observar as notícias publicadas no jornal "O Diário", verificouse que são matérias pagas, pois quem as escreve é a assessoria da CHTP. Isso indica que dificilmente este jornal produziria uma matéria denunciando esta empresa, pois gera lucro para o jornal.

No tocante ao presente trabalho, por intermédio das matérias selecionadas para interpretação, verificou-se que no dia 12 de agosto de 2016 o jornal "O Diário" trouxe a seguinte manchete: "Alunos do CRAS de Paranaíta conhecem projeto de reprodução de mudas da CHTP”. A matéria completa está escrita na página dois do jornal impresso. A foto que a acompanha traz várias crianças muito atentas, provavelmente ouvindo a coordenadora de Socioeconomia da CHTP. 
Figura 1- Crianças do CRAS em aula prática sobre preservação e recuperação da floresta

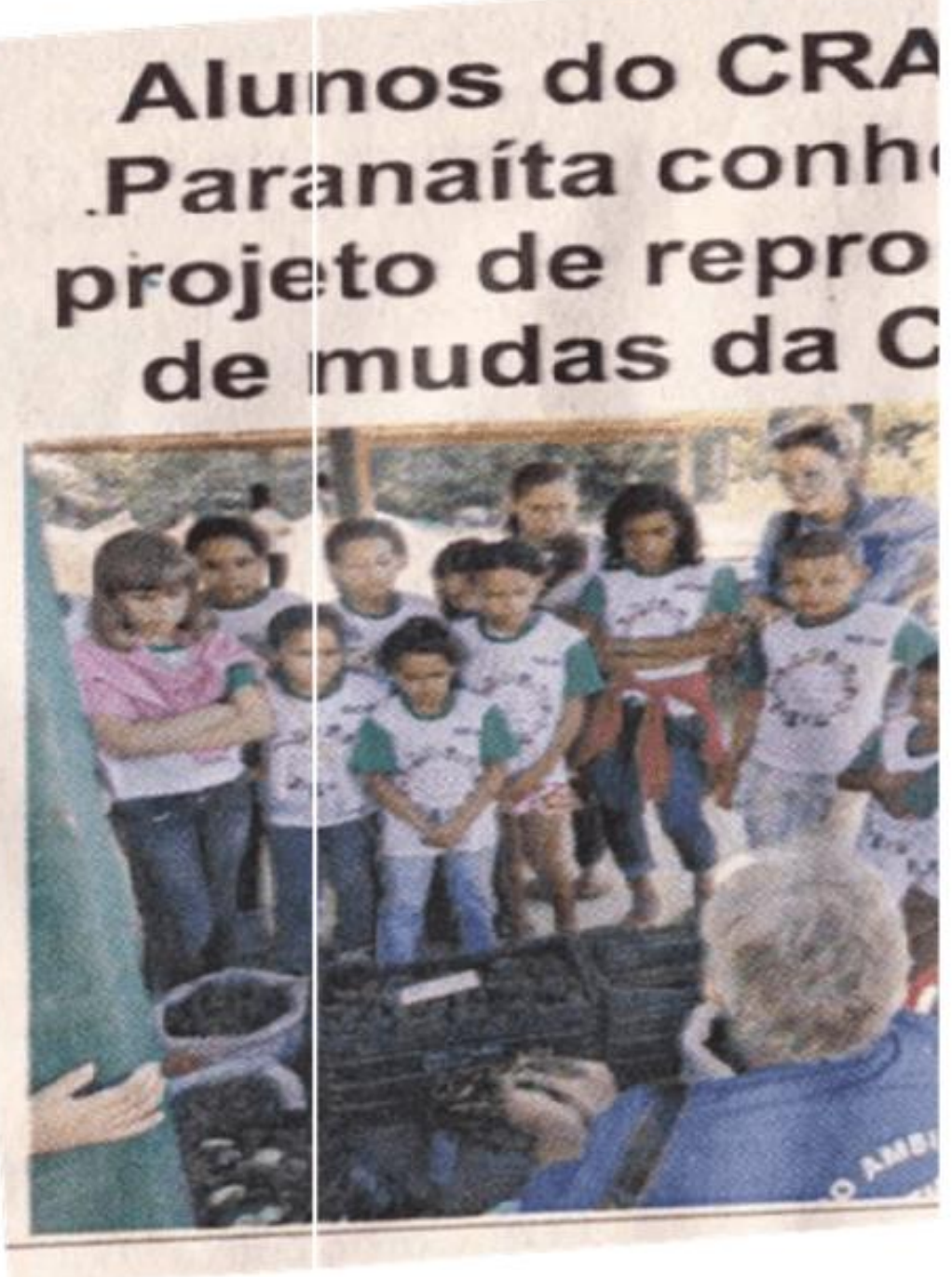

Fonte: O Diário, 12 de agosto de 2016, p. 2.

Ao observar a imagem, entende-se que a usina está desenvolvendo um trabalho educativo junto às crianças daquele município. Na matéria, há ainda a seguinte citação:

De acordo com a coordenadora da CHTP, Marileny Miranda, esse trabalho é de extrema importância para a preservação e recuperação da floresta nativa na região e também para o conhecimento científico já que 
existem poucos estudos relacionados à vegetação florestal do norte de Mato Grosso e Sul do Pará (ASSESSORIA DA CHTP, O diário, agosto de 2016, p. 2)

Quando cita-se a coordenadora da CHTP, o discurso do mito do pregresso vai se legitimando, mesmo que este acorra em um momento após o empreendimento já ter sido finalizado. O mito do progresso ganha agora uma nova abordagem: é preciso reconstruir o que foi destruído pela empresa atingida.

Ao dizer que esse trabalho de conscientização "[...] é de extrema importância para a preservação

a floresta nativa [...]", a empresa joga para a sociedade a responsabilidade pela não recuperação futura da floresta nativa que a barragem destruiu. Por outro lado, assume, de forma indireta, a culpabilidade de não ter realizado um estudo científico sobre as espécies de plantas nativas da região atingida, principalmente no local onde a barragem foi construída, quando cita que há poucos estudos sobre a vegetação florestal do norte de Mato Grosso e Sul do Pará.

Nesta mesma matéria, a assessoria utiliza a fala da psicóloga do CRAS, Silvana Tavares, que, segundo o texto, "[...] relatou que os alunos puderam conhecer mais uma atividade que é realizada no município[...]", no caso, Paranaíta. O que se depreende é que o discurso de que a CHTP está realizando suas obras de compensação e de mitigação na região atingida é legitimado pela expressão "mais uma atividade", como se a empresa estivesse contribuído e muito para o desenvolvimento da região norte de Mato Grosso e sul do Pará.

Consideramos importante destacar também outra fala da psicóloga do CRAS, que nos chama a atenção

A gente percebeu que não existem só impactos, que a CHTP está fazendo um trabalho de reflorestamento, se preocupando com o meio ambiente e as crianças entenderam como é o processo de coleta, a produção de mudas, como funciona o viveiro e a importância de se 
preservar o meio ambiente $\mathrm{e}$ isso vão levar para toda a vida. (ASSESSORIA DA CHTP, O Diário, 12 de agosto de 2016, p. 2).

Nesta fala, percebe-se que a CHTP vai se desfazendo a ideia de destruidora do meio ambiente. Pelo relato da psicóloga, verificou-se que, na visão dela, as atividades positivas da usina se sobrepõem aos impactos negativos, considerando a afirmação de que não houve impactos e que a CHTP está se preocupando com o meio ambiente ao fazer reflorestamento. Isso é paradoxal, pois a empresa, que destrói a natureza, agora ressurge dizendo que "se preocupa com o meio ambiente".

O discurso do mito do progresso deve se firmar e ser sempre reafirmado na região atingida. No caso da CHTP, deve ficar latente que esta veio para mudar para melhor a vida da população de onde barragem foi construída. Assim, a imprensa local e regional, autoridades e intelectuais, bem como os estudantes devem contribuir para defender o discurso da usina para toda a população. Nesse sentido, a matéria citada traz a fala do aluno Gabriel Augusto Paulo: "Achei muito bonito e entendi que se cortar e queimar todas as árvores o rio seca e tudo morre,". Pode-se perceber que Gabriel, em sua ignorância de menino talvez desconheça o tamanho da destruição causada ao meio ambiente e a toda a população atingida pela UHE Teles Pires.

No dia 17 de agosto de 2006, o Jornal “O Diário” publicou outra matéria assinada pela assessoria da CHTP, intitulada "CHTP apoia IV Seminário de Biodiversidade e Agroecossistemas Amazônicos em Alta Floresta". A CHTP não é a realizadora do evento, mas o apoia. Sendo assim, o título evidencia que a companhia está preocupada com a biodiversidade, ou seja, com os diversos tipos de vida que sofreram impactos diretos na implantação da barragem. Contudo, no discurso, jamais a empresa cita que ela é a principal causadora dos impactos negativos na natureza da região atingida.

Ao afirmar que apoia o agroecossistema, o que se mostra é um discurso evidenciando que o progresso está chegando, agora, em uma nova vertente, a do agrossistema. Afinal, até então, o avanço prometido não aconteceu, por isso, torna-se necessário reconfigurar o discurso. Ao ler o texto, descobre-se que a realizadora do evento é a 
Universidade Estadual de Mato Grosso (UNEMAT) e que a CHTP foi convidada a apoiar o evento, como se pode confirmar pela fala de João Cabeza, coordenador de Meio Ambiente da UHE Teles Pires

É muito gratificante para a UHE Teles Pires ter sido convidada para apoiar o evento da UNEMAT, que trata de um tema tão importante que é a alimentação humana com foco na sua importância econômica e ecológica. Sabemos da real necessidade de conciliar a produção de alimentos à preservação ambiental e, para isso, o desenvolvimento científico é um grande aliado. (ASSESSORIA DA CHTP, O Diário, 17de agosto de 2016, p. 2).

A fala do Senhor João Cabeza destaca que a usina foi convidada a apoiar o evento, e normalmente este tipo de apoio ocorre financeiramente. Ao nosso ver, isso mostra que o evento não traz a discussão dos impactos negativos causados pelo empreendimento no tocante à biodiversidade e ao agroecossistema amazônicos em Alta Floresta.

Afirmamos isso, pois a UNEMAT, como local de estudo e de formação crítica de cidadãos, e ainda onde o estudo científico se faz presente, ao nosso entender, não desempenha seu papel de debater com seriedade os investimentos da UHE Teles Pires na região atingida. Então, a instituição de ensino contribui para a propagação do discurso do mito do progresso da barragem. Afinal, a universidade mostra-se como uma forte aliada para a propagação do discurso da CHTP, visto ser um lugar interessante para se conquistar a elite intelectual. $O$ fato da empresa de barragem ter sido convidada a apoiar o evento realizado pela Universidade Estadual ou significa que aquela é bem-vista por esta ou que há apenas um jogo de interesse financeiro; em outras palavras, o convite do apoio ocorreu somente para se obter auxílio financeiro para a realização do evento.

Além disso, na matéria, desperta-nos o fato de que, embora seja um texto longo e ilustrado por um cartaz do Seminário, contraditoriamente a maior parte do texto visa informar sobre o evento, e até mesmo sobre um concurso de fotografia (já que a 
UNEMAT oferece também o curso de Jornalismo). Informa ainda sobre a avaliação dos trabalhos e a certificação dos participantes. Contudo, a ênfase à CHTP se dá somente no início do texto, até porque a

matéria é produzida pela assessoria da empresa, que se utiliza do evento para se manter na mídia e ser bem-vista pela população da região onde a barragem foi construída.

Em outra matéria publicada no mesmo jornal, no dia 27 de setembro de 2016, observou- se que a Companhia Hidrelétrica Teles Pires divulgou a seguinte notícia "CHTP promove plantio de mudas com criança do CRAS no Dia da Árvore". Ela chama a atenção, pois ocupa a manchete principal do jornal além de ser acompanhada por uma foto, que ocupa metade da página do jornal. Nessa foto, há várias crianças acompanhadas da psicóloga do CRAS e outras pessoas provavelmente representantes da UHE Teles Pires, todos em uma floresta, próximos a mudas de árvores e a uma placa na qual se lê "Dia da Árvore", como se pode verificar na foto abaixo:

Figura 2 - Crianças do CRAS juntamente com professores e representantes da CHTP no Dia da Árvore - Plantio de mudas.

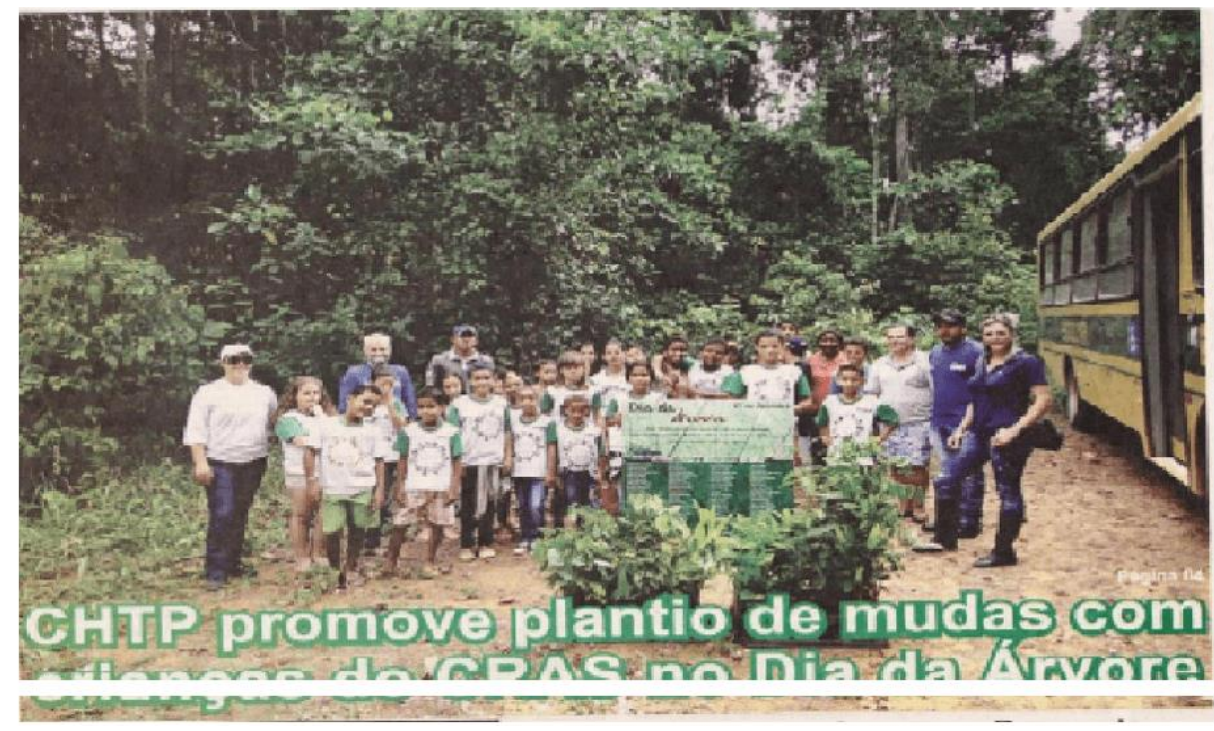

Fonte: O Diário, 27 de agosto, 2016, p. 4. 
Abaixo, está a manchete citada acima, a qual tem como protagonista a CHTP, como é possível notar: "CHTP promove plantio de mudas". A barragem e, então, colocada como o agente que realiza o plantio de árvores. A predominância da cor verde na foto, inclusive nas letras da manchete e no uniforme das crianças, reforça a ideia de que a usina está comprometida com a preservação das florestas.

Ao ler 0 texto da manchete, que se encontra na página 4, deparamo-nos com a informação de que o plantio ocorreu no entorno da estação de captação de água em Paranaíta, às margens do córrego Pinguim. A notícia enfatiza que a ação foi promovida pela CHTP, em parceria com as secretarias municipais de Meio Ambiente, de Obras e de Assistência Social. Essa informação legitima que o discurso do mito do progresso utilizado pelas empresas de barragens é respaldado por diversos agentes sociais e institucionais, pois estes

Utilizam diferentes formas e práticas: estudos técnicos, governos, seminários, reuniões, uso dos sistemas (Sebrae, Senai, etc), universidades, pesquisadores, escolas, empresas, falsas organizações, etc. Tudo isso para convencer e fazer com que a população aceite, apoie e até defenda seus projetos de exploração. Isso tem feito muita gente ficar do lado das empresas sem sequer saber o que está em jogo. (MOVIMENTO DOS ATINGIDOS POR BARRAGEM, p.11).

Como se pode denotar na citação acima, a tática discursiva envolve diversos agentes e estratégias discursivas variadas para convencer a população, principalmente, depois de destruir a região onde a barragem é construída, utilizar o discurso de que a empresa está preocupada com a natureza, com o bem-estar e com a qualidade de vida das pessoas atingidas pela barragem. Esse discurso fica latente na fala de Marcileny Miranda, coordenadora de Socioeconomia da CHTP

O córrego do Pinguim é responsável pelo abastecimento de água potável para a população de Paranaíta e em seu entorno existe um trecho de mata ciliar degradada que necessita ser recuperada para garantir a 
qualidade e a quantidade de água suficiente para atender Paranaíta. (ASSESSORIA DA CHTP, O Diário, 27 de agosto, 2016, p. 4)

O discurso da usina novamente é contraditório, pois a empresa que degrada a mata ciliar para construir a barragem se traveste de recuperadora da mesma, utilizando o discurso ecológico. Cuidar do meio ambiente, recuperando as florestas nativas e a água que abastece a cidade atingida, faz parte da estratégia de "vender" a ideia de um futuro melhor para a população que sofre os impactos. Dessa forma, a CHTP vai mudando a visão negativa que o empreendimento de barragem, traz, a princípio, ao povo da região atingida.

Outra fala que é mencionada no texto jornalístico é a do aluno Thalisson Gabriel Augusto, de 9 anos, que plantou, segundo a matéria, quatro mudas de árvores. Disse Thalisson: "É muito bom ver a natureza crescendo, a água produzindo. Essas árvores vão ajudar muito na conservação da água. Eu fiquei muito feliz". Nesta fala, pode-se perceber que o discurso do mito do progresso está sendo introduzido no modo de pensar das crianças. Esse estratagema é uma forma de a barragem renovar o seu discurso, o que faz lembrar o dos jesuítas, século XVII, cuja missão era catequizar o Novo Mundo.

O posicionamento da CHPT, nesse sentido, é construído para que a nova geração possa acreditar que o futuro depende da ação de preservação da natureza de cada pessoa que mora na região atingida. Nesse sentido, Dupas (2017) ressalta que

O progresso, assim como hoje é caracterizado nos discursos hegemônicos de parte dominante das elites, não é muito mais que um mito renovado por um aparato ideológico interessado em nos convencer que a história tem um destino certo - e glorioso - que dependeria mais da omissão embevecida das multidões do que da sua vigorosa ação e da crítica de seus intelectuais. (DUPAS, 2017, p. 89).

Finalizando, podemos certificar que a CHTP procura manter vivo o discurso do dito do progresso no norte de Mato Grosso, travestido agora pela ótica da preservação do 
meio ambiente. Para ganhar a confiança da população atingida pela barragem hidrelétrica, a empresa continua se inserindo no jornal "O Diário", com matérias escritas por sua Assessoria de Comunicação. No entanto, essas matérias são pagas, e têm o objetivo de impregnar o discurso de que a UHE Teles Pires está contribuindo para o desenvolvimento da região do norte de Mato Grosso, principalmente, por meio da preservação do meio ambiente.

Observa-se também que a imprensa local e regional, na maioria das vezes, contribui para a propagação do Discurso do Mito do Progresso. O jornal "O Diário" de Alta Floresta, pelo que se percebe, funciona como se fosse o diário oficial da CHTP, uma vez que está sempre divulgando as matérias da empresa.

Vale destacar, porém, que em regiões interioranas, onde há imprensa local, estas, de certa forma, necessitam sobreviver financeiramente. Então, uma empresa da magnitude da CHTP é uma fonte de lucro, e dificilmente a imprensa dessas regiões perderia a oportunidade de ver no empreendimento uma forma de ganhar dinheiro. Por outro lado, a empresa barrageira, ao contratar este serviço, não o faz inocentemente; tem notório conhecimento disso e vê nesta situação uma forma de "comprar" um aliado para expandir o seu discurso do mito do progresso.

\section{CONSIDERAÇÕES FINAIS}

Neste artigo, buscou-se analisar o discurso do mito do progresso utilizado pela Companhia Hidrelétrica Teles Pires (CHTP) veiculado na mídia de Alta Floresta, especificamente no jornal "O Diário". Escolheu-se este meio de comunicação por ter sido ele o objeto de estudo de nosso Trabalho de Conclusão de Curso em História pela Universidade Estadual de Mato Grosso (UNEMAT), em que analisou-se o discurso da CHTP veiculado neste jornal para convencer a população de Alta Floresta de que a construção da UHE Teles Pires era importante para o progresso da cidade e da região. Nele também notamos que a mídia era apenas reprodutora do discurso da usina, sendo as matérias assinadas pela assessoria da CHTP. 
Neste, artigo, no entanto, propomo-nos a avançar a respeito desta questão, evidenciando que o discurso do mito do progresso ainda está presente no discurso da CHTP, mesmo com o término da construção da UHE Teles Pires. Selecionamos as matérias publicadas nos meses de agosto e setembro de 2016, quando a empresa voltou à mídia, após um tempo de silenciamento, destacando suas atividades de preservação do meio ambiente. A partir disso, buscamos analisar este novo discurso, já que o progresso "vendido" na época da construção da barragem, não chegou.

Nesta análise, observamos que o discurso do mito do progresso empregado pela CHTP se renova e ressurge com uma outra roupagem: a de "protetora da natureza", Estabelece, assim, um discurso paradoxal, pois a mesma empresa destruiu o meio ambiente e justificou esta destruição alegando que a construção da barragem seria um passo para a vinda do progresso - o qual não chegou. Desse modo, o discurso do mito do progresso utilizado pela CHTP vai se renovando.

Vale destacar também que as obras de mitigação e de compensação não foram realizadas conforme manda a lei, pois é comum as empresas de barragem investirem o mínimo possível nestas obras. Sai mais barato para elas investirem em campanhas de conscientização e ações que envolvam a sociedade em datas comemorativas (Dia da Árvore, Outubro Rosa, Novembro Azul, etc.); dessa forma, a imagem negativa da empresa construtora de barragem vai sendo desconstruída. Verificamos, então, que CHTP não foge à regra, uma vez que utiliza esta estratégia que tem custo mais barato, e assim o discurso do mito do progresso vai se (re)construindo no ideário da população da região atingida pela barragem (no caso, o norte de Mato Grosso).

Ao concluir este artigo, temos a consciência de que o estudo proposto não se finaliza, pois, como já citado anteriormente, o discurso do mito do progresso está sempre se renovando. É preciso ficar atendo às novas estratégias utilizadas pelas empresas que "vendem" este discurso. Por ser mais barato do que que sustentar a verdade, o discurso do mito do progresso nunca morre; dessa forma, aprofundar o estudo deste tipo de discurso, além de necessário, significa buscar interpretar os agentes que constroem a história de uma cidade ou região. 


\section{REFERÊNCIAS}

ASSESSORIA DA CHTP. Alunos do CRAS de Paranaíta conhecem projeto de reprodução de mudas da CHTP. In: Jornal O Diário, Alta Floresta, 12 de agosto de 2016, p. 2, impresso.

. CHTP apoia IV Seminário de Biodiversidade e Agroecossistemas Amazônicos. In: Jornal O Diário. Alta Floresta, 17 de agosto de 2016, p. 2, impresso. CHTP promove plantio de mudas com crianças do CRAS no Dia da Árvore. Jornal. In: Jornal O Diário. Alta Floresta, 27 de Setembro, 2016, p. 4, impresso. BRESSER - PEREIRA, Luis Carlos. Desenvolvimento, progresso e crescimento econômico. Lua Nova, São Paulo, 93, 33- 60, 2014. [Versão online]

CHAVES, Sidney da Silva. Companhia Hidrelétrica Teles Pires e o discurso do mito do progresso veiculado na mídia de Alta Floresta - Trabalho de Conclusão de CursoUNEMAT, 2015.

DUPAS, Gilberto. O mito do progresso. In: Novos Estudos. 77. ed., CEBRAP, 2007. . O Mito do Progresso. São Paulo: Unesp, 2006.

FERREIRA, Aurélio Buarque de Holanda. Novo dicionário da língua portuguesa. 3. ed. Curitiba, 2004.

FIORIN, José Luiz. Linguagem e ideologia. 8. ed . São Paulo: Ática, 2007.

MARINS, Roberto Sergio. Ambiente e Desenvolvimento Regional. IN: Sociedade em Debates, Pelotas, 5(1): 59-80, abril, 1999.

MENDONÇA, Magno José Távora; PORTO, Jadson Luís Rebelo. Do Progresso à busca pelo meio ambiente equilibrado: a (in)compatibilidade da Tutela na Amazônia. Disponível em: <http://www.anppas.org.br/encontro4>. Acesso em: set. de 2016. 
MOVIMENTOS dos atingidos por barragens. A luta dos atingidos por barragens contra as transnacionais, pelos direitos por soberania energética. 2008 ( online)

NASCIMENTO, Aline Cristina; ROSA, Marcelo do Nascimento; AVELAR, Gilmar Alves. Condição para desenvolver - o papel dos empreendimentos hidrelétricos na produção do espaço capitalista. Estúdio Territorialies, São Paulo, 2014 [versão online]

PADUA, Suzana M. Mito da ideia do progresso. Disponível em: <http://www.oeco.org.br/ colunas/suzana-padua/o-mito-do-progresso/>. Acesso em: 25/09/2016.

PELLANDA, Patrícia Santos Précoma. A ideia de "Progresso" como reflexo ao desenvolvimento da Agrobiodiversidade no Brasil: o direito dos agricultores e os sistemas. Disponível em: <http://www.anppas.org.br/>. Acesso em: set. de 2016.

PICOLI, Fiorelo. Amazônia: do mel ao sangue- os extremos da expansão capitalista. 2. ed. Sinop: Fiorelo, 2005.

Amazônia: a ilusão da terra prometida. Sinop: Fiorelo, 2005. ROCHA, Everaldo. O que é mito. 7. ed. São Paulo: Brasiliense, 1994.

3. As três notícias estão disponíveis, na íntegra, nos anexos deste artigo. 


\section{ANEXOS}

ANEXO A- Alunos do CRAS de Paranaíta conhecem projeto de reprodução de mudas da CHTP

Cerca de 55 alunos das oficinas de dança e artesanato do Centro de Referênciade Assistência Social de Paranaita(Cras) conheceram, nos dias 28 e 29 de julho, os trabalhos realizadosno Viveiro deMudas Eco Vida, localizadonacomunidade Fintre Rios, no assentamento São Pedro. A unidade, cedida pela Prefeitura de Paranaita, mantida pela Companhia Hidrclétrica Teles Pires (CHTP), produz mudas de espécies nativas coletadas na região de abrangência da Hidrelétrica Teles Pires com objetivo de preservar as espécies por meio de ações de reflorestamento no empreendimento e seu entorno, alén de recuperação de áreas degradadas.

De acordo com a coordenadora de Sociocconomia da CHTP; Marcileny Miranda, esse

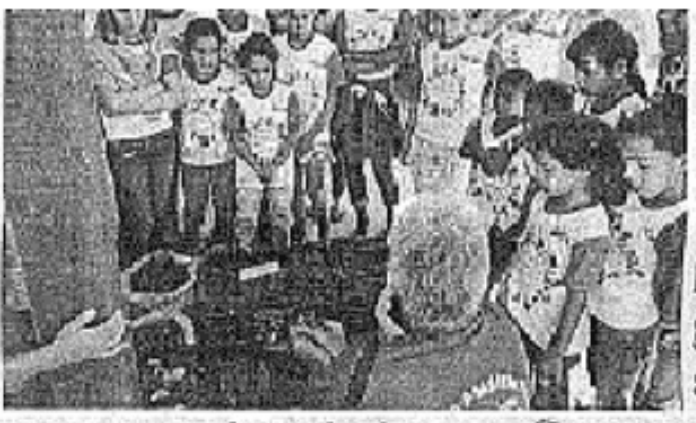
ta" explicou o coordenador do viveiro, Josć Piva.

A visita $\mathrm{fe} \%$ parte de una programação especial de férias do

poucos estudos relacionados àvegctação florestal do norte de Mato Grosso e Sul do Pará.

Acquipedo viveiroapresentou as alunos conno siio realizadas as ctapas de coleta de sementes na floresta, os equipamentos utilizados, - processo de separação e identificação das espécies, plantio, gemininaça dasplantas entre outras infomaç̧ões de forma participativa, "Os alunos viramna puática conso éfeitaa coleta de sementes pormeio da técrica derapel, participararn de uma peça de teatro interativa sobre a importancia das matas ciliarcs c da preservação ambiental efinalizaram avi-
Cras que atende criancas e adolesentes de 06 a 16 anos. A psicóloga do projeto, Silvaria Tavares, relatou que os alunos puderam conhecer mais uma atividiade queé realizada no município. " $\Lambda$ gente perceber que não existem só inpactos, quea CHTP está farendo um trabalho de reflorestamento, se preocupando com o meio ambiente cas crianças cintenderam como é o processo de coleta, a produção de mudas, como funcionao viveiro eaimportância de preservar o meio ambiente e isso, vão levar para toda a vida", pontuou. Oahuno Gabriel Augusto de Paulo, de oito anos, contou

Fonte: Jornal O Diário, Alta Floresta, 12 de agosto de 2016, p. 2, impresso. 


\begin{abstract}
ANEXO B - CHTP apoia IV Seminário de Biodiversidade e Agroecossistemas Amazônicos
\end{abstract}

2 CHITP apoila IV Seminário de Biodliversidade e
Agroecossistemas Amazônicos em Alta Floresta

Evento terá concurso de trabalhos científicos e fotografia



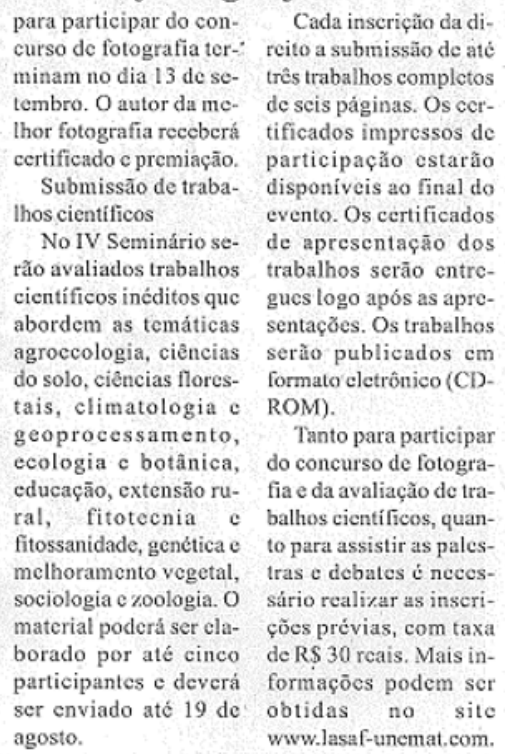

Fonte: Jornal O Diário, Alta Floresta, 17 de agosto de 2016, p. 2, impresso. 


\section{ANEXO C - CHTP promove plantio de mudas com crianças do CRAS no Dia da Árvore}

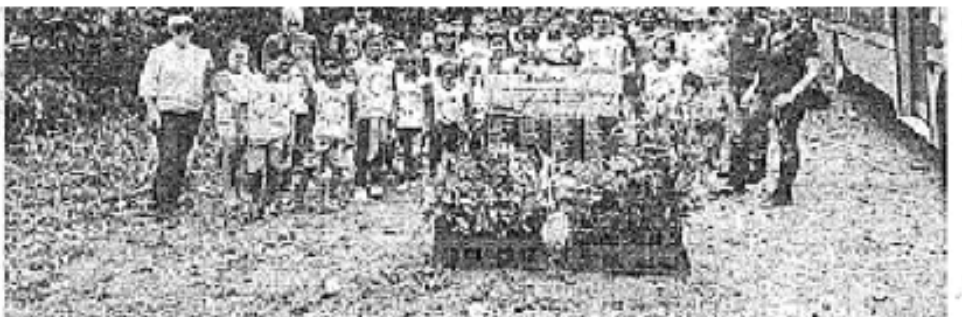

Assessoria da CHTP

Os nlunos dis Centro de Referencia de.Assistência Social de Paranaita (Cras), realizaram uma programaç⿰彳 bem ecol6gica no Dia da Árvore, comemorado em 21 de setembro. Eles participaram de uma ação de plantio cle mudas no entorno da estação de captação de agua cm Parsnníta, तोs mmrgens do córego Pinguim, promovida pela Companhia Hidrelótricn Teles Pires (CHTP) em parecria com as secretarias municipais de Meio Anbiente, Obras e de Assistencia Social.

A atividaule cousuu con ก porticipnçâก de $70 \mathrm{cri}$ anças e adolescentes, com idades entre seis e 15 ancs:s, yue plantarani cerca

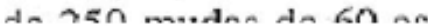

res" do CRAS.

"O córrego do Pinguim é responsável pelo abastecimento de água potável para a população de Paranaíla e em seu entorno existe um trecho de mata ciliar cegradacla que. necessita ser recuperada pirri garantir at qualidade e n quantidade de figua sufi ciente para atender Paranaíla. Coni essa parceria, loi possível lazer o plantio de mudas promovendo um trabalho de conscientizaçãu anbiental sobre n importfnciai clusi árvores na preservação da água", pontuou a coordenadora de Socioeconomia da CHTP, Mareileny Miraunda.

A equipe da empresa EloAmbicntal, responsável pela produçáo de mudas do viveiro Eco Vida, unidnds nus fan marta frow na conservaça da água. Fdl fiquei feliz de ajudar".

A psicólogn e técnica de referência do CRAS, Silvana Tavares, falou que as crianças ficeram sensibilizadas quando souberam (los: problen nas unbientais nas proximidades da área de captaçào de água da cidade deles. "Nús abrat çamos a causn. Essn é a segunda fase de una progr amaçāo de passeios do CRAS que busca salieniar a importância c a conscientização das criancuis e jovens quanto à necessidade de preservnção do meio ambiente e dis matas ciliares. Acredito que essa conscientizaçĩo ambicntal com ns criançns É importante tanto para elas, quanto para o município", concluiu a profissi onal.

Fin agostes as alunos conheceram os tmhalhos: realizados no viveiro do mudas tico Vicla, localizado na comuniclate Entre Rios, no Assentamento São Pedro. A unidade pro-

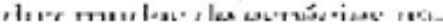

Fonte: Jornal “O Diário”, Alta Floresta, 27 de Setembro, 2016, p. 4,impresso.

Enviado: Fevereiro, 2020.

Aprovado: Março, 2020. 